\title{
Efeitos da Suplementação Prolongada de Creatina Mono-Hidratada sobre o Desempenho Anaeróbio de Adultos Jovens Treinados
}

\author{
Effects of Long-Term Creatine Monohydrate Supplementation on \\ Anaerobic Performance of Trained Young Adults
}

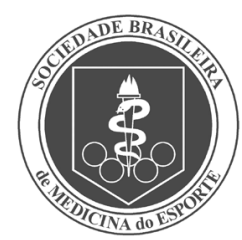

Artigo Original

\author{
Leandro Ricardo Altimari 1,3 \\ Julio Tirapegui ${ }^{2}$ \\ Alexandre Hideki Okano $1,3,4$ \\ Emerson Franchini ${ }^{5}$ \\ Monica Yuri Takito \\ Ademar Avelar ${ }^{4}$ \\ Juliana Melo Altimarí \\ Edilson Serpeloni Cyrino
}

1. GEPESINE - Grupo de Estudo e Pesquisa em Sistema Neuromuscular e Exercício, Departamento de Educação Física/CEFE. Universidade Estadual de Londrina (UEL), Londrina, PR, Brasil.

2. Departamento de Alimentos e Nutrição Experimental/FCF. Universidade de São Paulo, São Paulo (USP), SP, Brasil. 3. GEPEBIEX - Grupo de Estudo e

Pesquisa em Biologia Integrativa do Exercício. Departamento de Educação Física/CCS. Universidade Federal do Rio Grande do Norte (UFRN),

Natal, RN, Brasil.

4. GEPEMENE - Grupo de Estudo e Pesquisa em Metabolismo, Nutrição e Exercício, Departamento de Educação Física/CEFE. Universidade Estadual de Londrina (UEL), Londrina, PR, Brasil. 5. Escola de Educação Física e Esporte. Universidade de São Paulo (USP), São Paulo, SP, Brasil.

6. Faculdade de Educação Física. Universidade Estadual de Campinas (UNICAMP), Campinas, SP, Brasil.

\footnotetext{
Endereço para correspondência: Universidade Estadual de Londrina, Centro de Educação Física e Esportes, Departamento de Educação Física. Rod. Celso Garcia Cid, km 380,

Campus Universitário, 86051-990

Londrina, PR - Brasil.

E-mail: altimari@uel.br
}

\begin{abstract}
RESUMO
O objetivo do presente estudo foi investigar o impacto de oito semanas de suplementação de creatina mono-hidratada $\left(\mathrm{Cr}_{m}\right)$ sobre o desempenho anaeróbio de adultos jovens treinados. Vinte e seis estudantes de educação física, do sexo masculino, saudáveis, foram divididos aleatoriamente em grupo creatina (GCr, $\mathrm{n}=$ $13 ; 22,5 \pm 2,7$ anos; $74,9 \pm 6,8 \mathrm{~kg}, 178,5 \pm 4,8 \mathrm{~cm}$ ) e grupo placebo (GPI, $n=13 ; 22,9 \pm 3,2$ anos, $71,9 \pm 11,3 \mathrm{~kg}$ $178,6 \pm 4,0 \mathrm{~cm})$. Os indivíduos ingeriram em sistema duplo-cego doses de $\mathrm{Cr}_{\mathrm{m}}$ ou placebo-maltodextrina (20 g.d d $^{-1}$ por 5 dias e 3 g.d $\mathrm{d}^{-1}$ por 51 dias subsequentes). Ambos os grupos tiveram seus hábitos alimentares e os níveis de aptidão física controlados anteriormente. O teste anaeróbio de Wingate (TW) foi usado para avaliar o desempenho anaeróbio antes e após o período de ingestão de $\mathrm{Cr}_{\mathrm{m}}$ ou placebo. Os índices de desempenho analisados foram: potência pico relativa (PPR), potência média relativa (PMR), trabalho total relativo (TTR) e índice de fadiga (IF). Para tratamento estatístico foi utilizado ANOVA, seguido pelo teste de post hoc Tukey, quando $P<0,05$. Não foram observadas diferenças significantes nos índices PPR, PMR, TTR e IF após o período de suplementação de $\mathrm{Cr}_{m}(P<0,05)$. Os resultados do presente estudo sugerem que a suplementação de $\mathrm{Cr}_{m}$ não parece ser um recurso ergogênico eficiente em esforços físicos de alta intensidade e curta duração que envolve uma única série.
\end{abstract}

Palavras-chave: creatina, desempenho anaeróbio, fadiga, nutrição

\begin{abstract}
The objective of the present study was to investigate the impact of eight weeks of creatine monohydrate $\left(\mathrm{Cr}_{\mathrm{m}}\right)$ supplementation on the anaerobic performance of young trained adults. Twenty-six healthy male physical education students were randomly divided in creatine group ( $\mathrm{CrG}, \mathrm{n}=13 ; 22.5 \pm 2.7$ years; $74.9 \pm$ $6.8 \mathrm{~kg} ; 178.5 \pm 4.8 \mathrm{~cm}$ ) and placebo group ( $\mathrm{PIG}, \mathrm{n}=13 ; 22.9 \pm 3.2$ years; $71.9 \pm 11.3 \mathrm{~kg} ; 178.6 \pm 4.0 \mathrm{~cm})$. The subjects received in a double-blind system a $\mathrm{Cr}_{\mathrm{m}}$ or placebo-maltodextrin dose $\left(20 \mathrm{~g}^{-\mathrm{d}^{-1}}\right.$ for 5 days and 3 g. $\mathrm{d}^{-1}$ for 51 subsequent days). Both groups had their eating habits and levels of physical fitness previously controlled. The Wingate anaerobic test (WT) was used to evaluate the anaerobic performance before and after the ingestion period of $\mathrm{Cr}_{m}$ or placebo. The performance indexes assessed were: relative peak power (RPP), relative mean power (RMP), relative total work (RTW) and index of fatigue (IF). ANOVA followed by Tukey post hoc test were used when $P<0.05$ for statistical treatment. No significant difference in RPP, RMP, RTW or IF was observed after the period of supplementation of $\mathrm{Cr}_{m}(P>0.05)$. The results of the present study suggest that $\mathrm{Cr}_{m}$ supplementation does not seem to be an efficient ergogenic resource in high-intensity and short-duration efforts involving a single set.
\end{abstract}

Keywords: creatine, anaerobic performance, fatigue, nutrition

\section{INTRODUÇÃO}

A creatina mono-hidratada $\left(\mathrm{Cr}_{m}\right)$ tem sido usualmente utilizada por atletas e indivíduos fisicamente ativos, devido a seus possíveis efeitos ergogênicos sobre a massa muscular e o desempenho anaeróbio(1,2), com a vantagem de não apresentar risco aparente para a saúde ${ }^{(3,4)}$.

Durante exercícios de alta intensidade e curta duração, a hidrólise do trifosfato de adenosina (ATP) para a produção de energia é extremamente acentuada, o que provoca rápida utilização das reservas de fosfocreatina (PCr) para a ressíntese imediata de ATP(5). Assim, acreditase que os estoques de PCr no músculo possam ser fator limitante ou decisivo para o desempenho nesse tipo de exercício ${ }^{(6,7)}$. Estudos sugerem que o aumento nas reservas musculares de creatina total (CrT) e PCr, induzido pela suplementação de $\mathrm{Cr}_{m^{\prime}}$ possam aumentar a oferta de $\mathrm{PCr}$ e, consequentemente, acelerar a taxa de ressíntese de ATP durante o exercício físico, favorecendo a melhoria do desempenho em exercícios de alta intensidade e curta duração(8-10), apesar de isso não ser observado em todos os casos ${ }^{(11)}$. Acredita-se que o aumento das reservas de $\mathrm{PCr}$ possa favorecer o tamponamento da concentração de íons $\mathrm{H}^{+(5)}$, retardando o aparecimento da fadiga, uma vez que a PCr tem papel importante na conversão de adenosina difosfato (ADP) em ATP, a partir de reação reversível catalisada pela enzima creatina quinase $(C K)^{(6)}$. 
Parâmetros de desempenho anaeróbio como potência, trabalho e tempo para a exaustão voluntária, são obtidos facilmente e com alta reprodutibilidade em testes realizados em laboratório utilizando cicloergômetro ${ }^{(12)}$. Este modelo de exercício tem sido empregado para determinar a eficácia da suplementação de $\mathrm{Cr}_{\mathrm{m}}$ sobre o desempenho em exercícios de alta intensidade e curta duração, tanto em múltiplas séries como em uma única série de exercício ${ }^{(13)}$. O teste mais utilizado para este fim tem sido o teste anaeróbio de Wingate (TW), que consiste em esforço máximo contínuo, com duração de 30 segundos, realizado em cicloergômetro, com carga proporcional à massa corporal dos avaliados $^{(12)}$. Algumas investigações envolvendo a suplementação de $\mathrm{Cr}_{\mathrm{m}}$, em esforços máximos no cicloergômetro, têm apresentado resultados controversos, provavelmente pela falta de controle dietético prévio; controle dos níveis de condicionamento físico inicial, bem como durante o período de suplementação; suplementação em curtos períodos ( $\leq 7$ dias) e número reduzido de sujeitos nas amostras estudadas ${ }^{(14)}$.

Desta forma, o objetivo do presente estudo foi investigar o impacto de oito semanas de suplementação de $\mathrm{Cr}_{\mathrm{m}}$ sobre o desempenho anaeróbio de adultos jovens treinados, submetidos a controle dos níveis de aptidão física antes e durante o período de suplementação, bem como de hábitos alimentares.

\section{MÉTODOS}

\section{Sujeitos}

Vinte e seis alunos universitários do sexo masculino foram selecionados voluntariamente para participar deste estudo (tabela 1). Somente indivíduos que não estavam envolvidos em programas de treinamento estruturado e não tinham feito ingestão de qualquer suplemento nutricional contendo creatina mono-hidratada por seis meses anteriores ao estudo participaram do experimento. Os participantes foram classificados como insuficientemente ativos de acordo com o International Physical Activity Questionnaire (IPAQ), versão curta.

Todos os indivíduos foram informados sobre a proposta da pesquisa e assinaram um termo de consentimento livre e esclarecido de acordo com as normas do Conselho Nacional de Saúde sobre pesquisa envolvendo seres humanos. Este estudo foi aprovado pelo Comitê de Ética em Pesquisa da Faculdade de Ciências Farmacêuticas da Universidade de São Paulo.

\section{Delineamento experimental}

Os indivíduos foram submetidos inicialmente a protocolo de treinamento padronizado durante 19 semanas, que consistiu em três sessões semanais realizadas em dias alternados, com o propósito de igualar os níveis de condicionamento físico para garantir que todos os sujeitos iniciassem a suplementação de $\mathrm{Cr}_{\mathrm{m}}$ ou placebo, aparentemente com a mesma condição física. Após o protocolo de treinamento, os indivíduos foram divididos aleatoriamente em grupo suplementado $\mathrm{com} \mathrm{Cr}_{\mathrm{m}}(\mathrm{GCr} ; \mathrm{n}=13)$ e placebo (GPl; $n=13)$. O treinamento com pesos durante toda a fase de suplementação foi executado de forma alternada, em quatro sessões semanais, com o propósito de manter os níveis de condição física adquirida, a fim de minimizar qualquer tipo de interferência da condição física sobre o desempenho físico ${ }^{(14)}$. O programa de treinamento foi elaborado de acordo com a recomendação do ACSM(15) , orientado e supervisionado por uma equipe de profissionais de educação física durante todo o experimento. Os indivíduos foram orientados a não realizar qualquer tipo de atividade física regular durante o período de realização do estudo.

As medidas antropométricas para caracterização física dos indivíduos foi realizada antes da suplementação de $\mathrm{Cr}_{m}$ ou placebo. $\mathrm{O}$ registro alimentar para determinar os hábitos alimentares e o TW para avaliar o desempenho anaeróbio, foram aplicados antes e após a suplementação de $\mathrm{Cr}_{\mathrm{m}}$ ou placebo.
Os indivíduos foram orientados a não realizar nenhuma atividade física vigorosa, não fazer ingestão de substâncias com cafeína (café, chocolate, chá, guaraná em pó, alimentos e refrigerantes) ou alcoólicas, por 24 horas antes da realização do experimento, no intuito de evitar qualquer tipo de interferência nos resultados.

\section{Antropometria}

A massa corporal foi mensurada em balança digital (modelo PS180 ${ }^{\mathrm{TM}}$, Urano $^{\circledR}$, Brasil), com precisão de 0,1 kg, e a estatura determinada em estadiômetro de madeira com precisão de $0,1 \mathrm{~cm}^{(16)}$. Todos os sujeitos foram medidos com os pés descalços, vestindo apenas uma sunga. O índice de massa corporal (IMC) foi determinado pelo quociente peso/estatura ${ }^{2}$.

\section{Determinação dos hábitos alimentares}

Um grupo de nutricionistas, previamente treinadas, orientou os sujeitos no preenchimento dos registros de consumo alimentar de sete dias na semana antecedente à aplicação do TW em ambos os momentos e a manter os seus hábitos alimentares durante todo o período de suplementação. Medidas caseiras padronizadas foram utilizadas para estimar a quantidade de comida e bebida consumida. As proporções dos macronutrientes foram determinadas através do programa de avaliação nutricional Virtual Nurtri ${ }^{\mathrm{T}}$, versão 1.0 (Nupens, FSPUSP, Brasil). A ingestão de água foi ad libitum.

\section{Suplementação de creatina mono-hidratada}

Após os participantes do presente estudo serem separados aleatoriamente, receberam $\mathrm{Cr}_{m}$ ou placebo (maltodextrina) (Integralmédica S/A, Agricultura e Pesquisa, Brasil) em sistema duplo cego por oito semanas. Os suplementos foram oferecidos em forma de cápsulas com cor e textura semelhantes com intenção de evitar que os sujeitos reconhecessem o conteúdo das substâncias. Durante os primeiros cinco dias da fase de suplementação, os sujeitos ingeriram 20g.d ${ }^{-1}$ de $\mathrm{Cr}_{\mathrm{m}}$ ou placebo, em quatro doses similares de $5 \mathrm{~g}$, a cada três-quatro horas. Nos 51 dias subsequentes, somente uma dose de $3 \mathrm{~g}^{-\mathrm{d}^{-1}}$ foi consumida. Os sujeitos foram orientados a ingerir as doses de suplementação associadas a $250 \mathrm{~mL}$ de bebida carbo-hidratada ${ }^{(18)}$.

\section{Desempenho anaeróbio}

O desempenho anaeróbio foi determinado por meio da aplicação do TW ${ }^{(12)}$ em cicloergômetro mecânico de membro inferior (Monark ${ }^{\circledR}$ 324e, Suécia), com precisão de 0,25kpm, adaptado com sensor óptico para contagem de revoluções. Os indicadores de desempenho anaeróbio foram obtidos por meio de programa computadorizado que possibilitou a obtenção da potência pico relativa (PPR), potência média relativa (PMR), trabalho total relativo (TTR) e índice de fadiga (IF) (Figura 1).

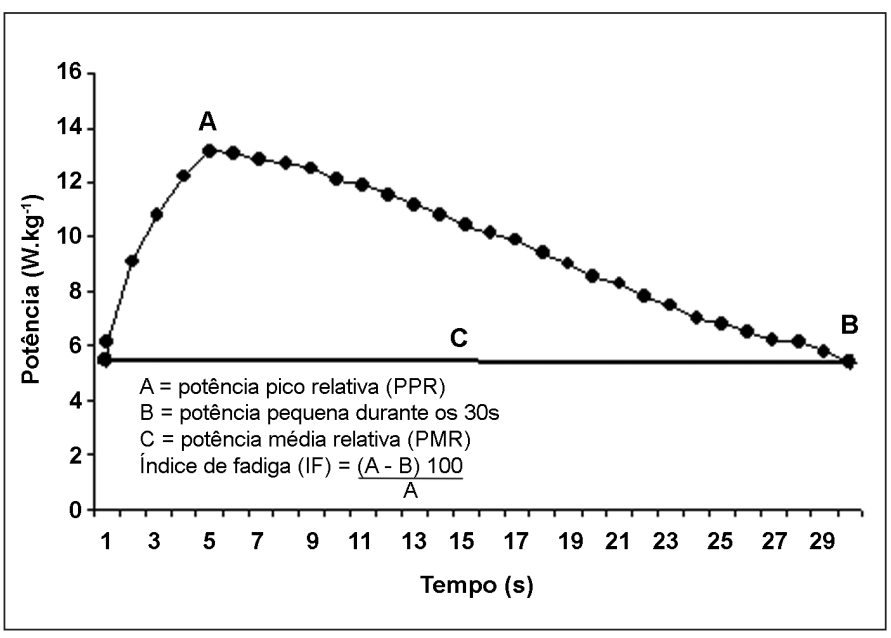

Figura 1. Indicadores de desempenho anaeróbio obtidos no Teste de Wingate. 
O protocolo consistiu de aquecimento de cinco minutos, com carga de 0,5kpm, e cadência de pedaladas de 70rpm. No início de cada minuto os indivíduos executaram um sprint de seis segundos que fez parte do processo de familiarização do TW ${ }^{(19)}$. Após o aquecimento, adotou-se intervalo de dois minutos para medida da massa corporal, ajuste da altura do banco da bicicleta e ajuste da intensidade de esforço. Logo depois, os indivíduos, sem qualquer rotação prévia, iniciaram o TW com carga corresponde a 9\% da massa corporal ${ }^{(20)}$. Depois de finalizado o teste, os sujeitos realizaram recuperação ativa no próprio cicloergômetro, sem resistência, por um período de três minutos, na tentativa de minimizar possíveis efeitos colaterais provocado pelo esforço físico.

\section{Parâmetros bioquímicos}

Foram coletados $25 \mu \mathrm{L}$ de sangue na orelha, um minuto após a realização do TW, para dosagem da concentração de lactato sanguíneo [La]. As amostras foram imediatamente armazenadas em tubos de polietileno com capacidade de $1,5 \mathrm{~mL}$, e posteriormente estocados a $-70^{\circ} \mathrm{C}$. Cada tubo continha $50 \mu \mathrm{L}$ de solução de anticoagulante (fluoreto de sódio, 1\%). A [La] foi determinada 24 horas após o término das coletas em um analisador eletroquímico Yellow Springs 1500 Sport $^{\text {TM }}$ (Yellow Springs, EUA), que foi calibrado antes do início das análises e a cada cinco amostras, tendo como referência uma [La] conhecida (5mmol. $\left.\mathrm{L}^{-1}\right)$ disponibilizada pela Yellow Springs.

Para a determinação das concentrações de creatinina [CR] foram feitas coletas de urina de 24 horas antes e após o período de suplementação de $\mathrm{Cr}_{m}$ ou placebo. A coleta de urina de 24 horas foi iniciada a partir da segunda micção de um determinado dia, prolongando-se até a primeira do dia seguinte(21).

Após o volume urinário total ser registrado, uma alíquota de 5-10mL foi separada em frascos coletores de urina de plástico e, em seguida, armazenada em congelador a $-70^{\circ} \mathrm{C}$. As amostras de urina foram analisadas 48 horas após as coletas em espectrofotômetro UV-VIS TM (Shimadzu Mini 1240, Japão), utilizando kit creatinina cinética colorimétrica ${ }^{\text {TM }}$ (Celm, Brasil), por meio do método cinético colorimétrico a 500 $\mathrm{nm}^{\text {(22) }}$.

\section{Tratamento estatístico}

As características físicas do GCr e GPI foram comparadas utilizando teste $t$ de Student, para amostras independentes, com o mesmo número de elementos. Após verificação dos pressupostos exigidos para a utilização da análise de variância a partir do teste de normalidade de Shapiro Wilk e de homogeneidade de Levene, a análise de variância (Anova) 2 × 2 foi utilizada para avaliar possíveis modificações na proporção de macronutrientes consumidos, [La], [CR] e índices de desempenho anaeróbio, dos dois grupos (GCr e GPI) ao longo do tempo (pré e pós-suplementação). O teste post hoc de Tukey foi utilizado para identificar diferenças nas variáveis quando valores de $\mathrm{F}$ foram superiores ao critério estabelecido para nível de significância de 5\%.

\section{RESULTADOS}

As características físicas dos GCr e GPI são apresentados na tabela 1. Não houve diferença estatisticamente significante na comparação entre os grupos no momento inicial do estudo $(P>0,05)$.

Tabela 1. Características físicas dos grupos suplementados com $\mathrm{Cr}_{m}(\mathrm{GCr})$ e placebo (GPI).

\begin{tabular}{c|c|c|c|c}
\hline & $\begin{array}{c}\text { Idade } \\
\text { (anos) }\end{array}$ & $\begin{array}{c}\text { Massa corporal } \\
\mathbf{( k g )}\end{array}$ & $\begin{array}{c}\text { Estatura } \\
\mathbf{( c m})\end{array}$ & $\begin{array}{c}\text { IMC } \\
\mathbf{( k g / \mathbf { m } ^ { 2 } )}\end{array}$ \\
\hline $\mathrm{GCr}(\mathrm{n}=13)$ & $22,5 \pm 2,7$ & $74,9 \pm 6,8$ & $178,5 \pm 4,8$ & $23,4 \pm 2,6$ \\
\hline $\mathrm{GPI}(\mathrm{n}=13)$ & $22,9 \pm 3,2$ & $71,9 \pm 11,3$ & $178,6 \pm 4,0$ & $22,5 \pm 3,0$ \\
\hline
\end{tabular}

Foi constatado, neste estudo, que ambos os grupos apresentaram semelhantes níveis de aptidão física antes e durante o período de suplementação, uma vez que os níveis de força muscular dos membros inferiores, superiores e de tronco não apresentaram diferenças estatisticamente significantes entre os dois grupos nos diferentes momentos do estudo $(P>0,05)$.

Com relação aos hábitos alimentares, nenhuma modificação significante foi encontrada nas proporções de macronutrientes consumidos pelos $\mathrm{GCr}$ e GPI, nos momentos pré e pós-suplementação $(P>0,05)$ (tabela 2).

Tabela 2. Valores das proporções de macronutrientes consumidos pelos grupos suplementados com $\mathrm{Cr}_{m}$ (GCr) e placebo (GPI).

\begin{tabular}{l|c|c|c|c|c}
\hline & $\mathbf{G C r}(\mathbf{n}=\mathbf{1 3})$ & $\mathbf{G P I}(\mathbf{n}=\mathbf{1 3})$ & Efeitos & $\mathbf{F}$ & $\boldsymbol{P}$ \\
\hline Carbo-hidratos (\%) & & & & & \\
\hline Pré & $49,4 \pm 3,5$ & $50,3 \pm 3,0$ & grupo & 0,32 & 0,57 \\
\hline Pós & $49,7 \pm 3,6$ & $50,3 \pm 2,8$ & tempo & 1,40 & 0,44 \\
\hline & & & grupo X tempo & 0,07 & 0,79 \\
\hline Proteínas (\%) & & & & & \\
\hline Pré & $16,4 \pm 1,6$ & $16,1 \pm 1,7$ & grupo & 0,01 & 0,91 \\
\hline Pós & $16,4 \pm 1,5$ & $16,6 \pm 1,8$ & tempo & 1,14 & 0,48 \\
\hline & & & grupo X tempo & 2,31 & 0,14 \\
\hline Lipídios (\%) & & & & & \\
\hline Pré & $34,1 \pm 4,4$ & $33,6 \pm 3,3$ & grupo & 0,19 & 0,66 \\
\hline Pós & $33,8 \pm 4,2$ & $33,1 \pm 2,4$ & tempo & 10,15 & 0,19 \\
\hline & & & grupo X tempo & 0,10 & 0,75 \\
\hline
\end{tabular}

Nota: Os dados são expressos em médias \pm DP.

Os valores correspondentes aos parâmetros de desempenho anaeróbio, PPR, PMR, TTR e IF, encontrados nos grupos GCr e GPI, nos diferentes momentos do estudo, são apresentados na tabela 3. Nenhum efeito que pudesse ser atribuído à suplementação de $\mathrm{Cr}_{\mathrm{m}}$ foi verificado

Tabela 3. Valores dos parâmetros de desempenho anaeróbio dos grupos suplementados com $\mathrm{Cr}_{\mathrm{m}}(\mathrm{GCr})$ e placebo (GPI).

\begin{tabular}{l|c|c|c|c|c}
\hline & $\mathbf{G C r}(\mathbf{n}=\mathbf{1 3})$ & $\mathbf{G P I}(\mathbf{n}=\mathbf{1 3})$ & Efeitos & $\mathbf{F}$ & $\boldsymbol{P}$ \\
\hline PPR $\left(\mathrm{W} . k g^{-1}\right)$ & & & & & \\
\hline Pré & $12,2 \pm 1,1$ & $11,5 \pm 1,2$ & grupo & 1,59 & 0,22 \\
\hline Pós & $13,0 \pm 1,1$ & $12,7 \pm 1,1$ & tempo & 28,20 & $<0,01$ \\
\hline PMR $\left(\mathrm{W} . k g^{-1}\right)$ & & & grupo X tempo & 0,52 & 0,48 \\
\hline Pré & $9,1 \pm 0,7$ & $8,9 \pm 0,7$ & grupo & 2,15 & 0,15 \\
\hline Pós & $9,4 \pm 0,6$ & $9,0 \pm 0,5$ & tempo & 3,50 & 0,08 \\
\hline TTR $(J . k g-1)$ & & & grupo X tempo & 0,47 & 0,50 \\
\hline Pré & $273,7 \pm 21,6$ & $266,5 \pm 20,0$ & grupo & 0,96 & 0,33 \\
\hline Pós & $282,7 \pm 18,1$ & $275,3 \pm 22,9$ & tempo & 7,49 & $<0,01$ \\
\hline Pós & $51,0 \pm 9,4$ & $53,8 \pm 7,0$ & tempo & 2,80 & 0,11 \\
\hline IF $(\%)$ & & & grupo X tempo & 0,01 & 0,97 \\
\hline Pré & & & & 2,94 & 0,08 \\
\hline
\end{tabular}

Nota: Os dados são expressos em médias \pm DP. PPR = potência pico relativa; PMR = potência media relativa; TTR $=$ trabalho total relativo; $\mathrm{IF}=$ índice de fadiga. 
nos indicadores de desempenho anaeróbio $(P>0,05)$, embora tenha sido observado efeito isolado do tempo na PPR e TTR $(P<0,01)$. Nenhuma alteração significante foi verificada em relação ao IF, após a suplementação de $\mathrm{Cr}_{\mathrm{m}}$.

Os valores de [La] e [CR] dos grupos GCr e PIG nos momentos pré e pós-suplementação são apresentados na tabela 4. Não foi verificada alteração significante na [La], entre os momentos pré e póssuplementação, em ambos os grupos estudados $(P>0,05)$. Com relação a $[C R]$, verificou-se interação significante entre grupo e tempo $(P<$ 0,03), embora o aumento após a suplementação no $\mathrm{GCr}$, não tenha sido estatisticamente confirmado $(P>0,05)$.

Tabela 4. Valores de concentração de lactato sanguíneo [La] e de creatinina urinária [CR] dos grupos suplementados com $\mathrm{Cr}_{m}$ (GCr) e placebo (GPI).

\begin{tabular}{l|c|c|c|c|c}
\hline & $\mathbf{G C r}(\mathbf{n}=\mathbf{1 3})$ & $\mathbf{G P I}(\mathbf{n}=\mathbf{1 3})$ & Efeitos & $\mathbf{F}$ & $\boldsymbol{P}$ \\
\hline [La] $\left(\mathrm{mmol} . \mathrm{L}^{-1}\right)$ & & & & & \\
\hline Pré & $10,6 \pm 1,2$ & $10,0 \pm 1,8$ & grupo & 0,20 & 0,65 \\
\hline Pós & $10,1 \pm 1,6$ & $10,2 \pm 2,1$ & tempo & 0,28 & 0,60 \\
\hline & & & grupo X tempo & 0,85 & 0,37 \\
\hline [CR] (g/dia) & & & & & \\
\hline Pré & $1,6 \pm 0,2$ & $1,4 \pm 0,3$ & grupo & 0,29 & 0,61 \\
\hline Pós & $1,8 \pm 0,3$ & $1,4 \pm 0,2$ & tempo & 0,55 & 0,49 \\
\hline \multicolumn{7}{l}{} \\
\hline
\end{tabular}

\section{DISCUSSÃO}

Estudos prévios têm sugerido que a suplementação de $\mathrm{Cr}_{m}$ melhora o desempenho em exercícios de alta intensidade e curta duração(2). Assim, o presente estudo investigou o efeito de oito semanas de suplementação de $\mathrm{Cr}_{m}$ sobre o desempenho anaeróbio no TW de adultos jovens treinados, submetidos a controle dos níveis de aptidão física antes e durante o período de suplementação, bem como de hábitos alimentares.

Considerando a importância de controlar os níveis de aptidão física dos sujeitos envolvidos no experimento, o presente estudo optou em utilizar o modelo de treinamento com pesos (exercícios resistidos), uma vez que este possibilita a adoção de programas de treinamento que podem contemplar grande número de indivíduos ao mesmo tempo, tornando possível um controle sistematizado do volume e intensidade do treinamento e do período de recuperação ${ }^{(15)}$. Desse modo, foi possível constatar que ambos os grupos apresentaram semelhantes níveis de aptidão física antes e durante o período de suplementação. O controle prévio do treinamento e da manutenção deste ao longo do período de suplementação se baseou na hipótese de que diferentes níveis de aptidão física poderiam produzir diferentes resultados sobre o desempenho, dificultando a comparação entre os grupos nos diferentes momentos do estudo e, consequentemente, a explicação sobre o verdadeiro potencial ergogênico da $\mathrm{Cr}_{\mathrm{m}}{ }^{(14)}$.

Foi verificado neste estudo, ainda, que ambos os grupos apresentaram hábitos alimentares semelhantes ao longo do período de suplementação. A proposta de controle prévio dos hábitos alimentares dos indivíduos investigados foi baseada na hipótese de que uma alta ingestão de proteínas, preferencialmente de origem animal, poderia minimizar as respostas para esse tipo de suplementação ${ }^{(14)}$. Por outro lado, os indivíduos, geralmente vegetarianos, podem se beneficiar dessa estratégia, uma vez que possuem pequenas reservas de Cr intramuscular, bem como de $\mathrm{PCr}{ }^{(23)}$. Vale ressaltar que nenhum dos indivíduos investigados era vegetariano.
Os resultados do presente estudo relacionados ao TW não demonstraram melhora significante nos indicadores de desempenho anaeróbio para o grupo que ingeriu $\mathrm{Cr}_{\mathrm{m}}$ (20 g.d $\mathrm{d}^{-1}$ por cinco dias, seguindo por $3 g . d^{-1}$ por 51 dias). O efeito da suplementação de $\mathrm{Cr}_{m}$ por curto período de tempo ( $\leq 7$ dias), também tem apresentado resultados semelhantes aos achados deste estudo. Odland et al.(24) estudando o desempenho em uma única série no TW de indivíduos moderadamente treinados suplementados com $\mathrm{Cr}_{m}$ (20 g.d d $^{-1}$ por três dias), não observaram melhorias significantes na PPR, PMR, TTR e IF. Resultados semelhantes foram encontrados em estudos que pesquisaram os efeitos da ingestão de doses de $\mathrm{Cr}_{\mathrm{m}}$ que variou entre 20 e $30 \mathrm{~g} . \mathrm{d}^{-1}$ por cinco dias, sobre o desempenho anaeróbio em uma única série no cicloergômetro, com duração dos sprints variando de 10 a 20 segundo(25-27).

Da mesma forma, estudos que examinaram múltiplas séries (duas e três séries) no TW não encontraram melhoria significante no desempenho anaeróbio do primeiro sprint para os indicadores PPR(28-31), $\mathrm{PMR}^{(13,28,31,32)}$ e IF ${ }^{(32)}$ após a ingestão de doses variadas de $\mathrm{Cr}_{\mathrm{m}}$ (20 a 35 g. $\mathrm{d}^{-1}$ ) ingeridas entre períodos de quatro a 14 dias. Considerando esses achados, podemos sugerir que o período de suplementação não parece ser fator decisivo para a melhoria do desempenho anaeróbio em uma única série de esforço no TW, uma vez que, em nosso estudo, o período de suplementação utilizado foi longo (oito semanas). É importante ressaltar que o aumento nas reservas musculares de $\mathrm{Cr}$, PCr e $\mathrm{CrT}$ em repouso, tem sido demonstrado após longos ( $\geq 7$ dias) $)^{(9,33)}$ e curtos (quatro-cinco dias) ${ }^{(10,21)}$ períodos de suplementação com $\mathrm{Cr}_{\mathrm{m}}$.

Em compensação, alguns estudos verificaram melhorias significantes nos indicadores de desempenho anaeróbio $\operatorname{PPR}^{(32,34,35)}$, $\mathrm{PMR}^{(10,34,35)}$, $\operatorname{TTR}^{(29,30,34-36)}$ e IF ${ }^{(31,35)}$ no primeiro sprint de múltiplas séries no TW (duas e três séries), após a ingestão de doses variadas de $\mathrm{Cr}_{m}$ (20 a 35 g.d $\mathrm{d}^{-1}$ ) ingeridas entre períodos de quatro a 14 dias. Essas melhorias têm sido atribuídas ao aumento nas reservas intramusculares de $\mathrm{Cr}$, PCr e CrT, induzido pela suplementação de $\mathrm{Cr}_{m}$, que parece aumentar a disponibilidade de PCr e, consequentemente, acelerar a ressíntese de ATP, durante os esforços de alta intensidade e curta duração ${ }^{(9,10)}$. Considerando essas informações, podemos sugerir que as diferenças encontradas na presente investigação, em relação aos estudos citados anteriormente, parecem acontecer, pelo menos em parte pele falta de controle prévio do treinamento e da manutenção deste ao longo do período de suplementação, bem como controle dos hábitos alimentares dos sujeitos participantes desses estudos. A literatura tem relatado que a falta de controle dessas variáveis podem produzir diferentes resultados sobre o desempenho(14).

Além disso, é possível que indivíduos com níveis semelhantes de aptidão física (treinados) que fazem uso de $\mathrm{Cr}_{m}$, quando submetidos a esforços de alta intensidade e curta duração em uma única série, podem usar suas reservas de PCr para a ressíntese de ATP na mesma proporção que indivíduos não suplementados com $\mathrm{Cr}_{\mathrm{m}^{\prime}}$ considerando que os depósitos de PCr desses indivíduos (não suplementados), quando estes apresentam dieta adequada parece ser suficiente para suportar um esforço único ${ }^{(7,37,38)}$. Portanto, acreditamos que a suplementação de $\mathrm{Cr}_{m}$ possa ser realmente eficiente em esforços de alta intensidade e curta duração que envolva múltiplas séries contribuindo na aceleração da ressíntese de ATP, uma vez que a degradação das reservas de $\mathrm{PCr}$ neste tipo de esforço é evidente $\mathrm{e}^{(9,10,13,30)}$.

Alguns estudos têm demonstrado aumento significante na [La] e íons $\mathrm{H}^{+}$, além da redução de íons $\mathrm{HCO} 3$ e pH sanguíneos após esforço máximo no cicloergômetro com duração entre seis e 10 segundos, bem como após o TW( ${ }^{(39,40)}$. No presente estudo, a [La] após o TW não sofreu alteração significante entre os momentos pré e pós-suplementação de $\mathrm{Cr}_{\mathrm{m}}$, o que não suporta a teoria de que o aumento das reservas de $\mathrm{PCr}$ poderia ajudar no tamponamento dos íons $\mathrm{H}^{+}$e atrasar a instalação da fadiga como sugerem alguns pesquisadores ${ }^{(5,6)}$. 
A discussão sobre o efeito da suplementação de $\mathrm{Cr}_{m}$ sobre a [La], após a execução de uma única série e após o primeiro sprint de múltiplas séries no cicloergômetro, com duração variando entre 10 e 30 segundos, tem apresentado algumas controvérsias. Enquanto alguns estudos têm apresentado queda ${ }^{(8,41,42)}$, outros têm que indicado manutenção( $24,26,27,30,36)$ ou aumento ${ }^{(32,38)}$ na [La] após a suplementação de $\mathrm{Cr}_{\mathrm{m}}$. Os diferentes resultados de [La] encontrados nos estudos podem ser explicados, em parte, pela grande variabilidade inter-individual(43).

Quanto à taxa de [CR], embora não se tenha verificado aumento significante no grupo que ingeriu $\mathrm{Cr}_{\mathrm{m}}$ após o período de suplementação, efeito significante entre grupo e tempo foi confirmada, indicando que o GCr teve taxa de [CR] maior quando comparada ao GPI. Desse modo, embora não tenha sido realizado biópsia muscular no presente estudo, os resultados sugerem que os sujeitos suplementados com $\mathrm{Cr}_{\mathrm{m}}$ tiveram suas reservas intramusculares de $\mathrm{Cr}$ aumentadas(37).

Embora o efeito da maior oferta de $\mathrm{Cr}_{m}$ para o organismo seja melhor avaliado através de biópsia muscular, bem como a partir da análise de Cr no plasma e na urina, a análise da [CR] tem se mostrado eficiente para avaliar a retenção de $\mathrm{Cr}$ no organismo(21). Assim, muitos estudos têm utilizado a coleta de urina de 24 horas para determinar a [CR]. Esses estudos têm encontrado taxa de [CR] significativamente maior após a suplementação $c o m \mathrm{Cr}_{m}{ }^{(10,21,44)}$. Esse efeito tem sido atribuído à maior oferta de $\mathrm{Cr}_{\mathrm{m}}$ ao organismo(1).

Portanto, a partir dos resultados do presente estudo, podemos concluir que a suplementação de $\mathrm{Cr}_{\mathrm{m}}\left(20 \mathrm{~g}\right.$.d $\mathrm{d}^{-1}$ por cinco dias, seguida de $3 \mathrm{~g} \cdot \mathrm{d}^{-1}$ por 51 dias), não melhora o desempenho anaeróbio de adultos jovens treinados em uma única série no TW, mesmo com controle dos níveis de aptidão física e hábitos alimentares antes e durante o período de suplementação. Considerando os achados do presente estudo, sugerimos a realização de estudos que investiguem o efeito da suplementação de $\mathrm{Cr}_{\mathrm{m}}$ e contemple em seu delineamento experimental exercícios de múltiplas séries associados a controle dos níveis de aptidão física e hábitos alimentares.

\section{AGRADECIMENTOS}

Os autores agradecem à Fapesp, o CNPq e a Capes, pelas bolsas de pós-graduação outorgadas.

Todos os autores declararam não haver qualquer potencial conflito de interesses referente a este artigo.

\section{REFERÊNCIAS}

1. Mesa JL, Ruiz JR, Gonzalez-Gross MM, Gutierrez-Sainz A, Castillo Garzon MJ. Oral creatine supplementation and skeletal muscle metabolism in physical exercise. Sports Med 2002;32:903-44.

2. Branch JD. Effect of creatine supplementation on body composition and performance: a meta-analysis. Int J Sport Nutr Exerc Metab 2003;13:198-226.

3. Persky AM, Rawson ES. Safety of creatine supplementation. Subcell Biochem 2007;46:275-89.

4. Brudnak MA. Creatine: are the benefits worth the risk? Toxicol Lett 2004;150:123-30.

5. Pischel I, Gastner T. Creatine: its chemical synthesis, chemistry, and legal status. Subcell Biochem 2007:46:291-307.

6. Hultman E, Greenhaff PL, Ren JM, Soderlund K. Energy metabolism and fatigue during intense muscle contraction. Biochem Soc Trans 1991;19:347-53.

7. Allen DG, Lamb GD, Westerblad H. Skeletal muscle fatigue: cellular mechanisms. Physiol Rev 2008; 88:287-332.

8. Balsom PD, Söderlund K, Sjödin B, Ekblom B. Skeletal muscle metabolism during short duration highintensity exercise: influence of creatine supplementation. Acta Physiol Scand 1995;154:303-10.

9. Cooke CB, Theodorou A, King RFGJ, Gibbon W, Frain M. The effects of a creatine maintenance dosage on muscle metabolites and anaerobic performance. Med Sci Sports Exercise 1999;31:S354.

10. Havenetidis K, Theodorou A, Cooke CB, King RFGJ. Effects of an acute Cr loading on muscle metabolites and anaerobic performance. In: Annual Congress of the European College of Sport Science, Atenas, 2002. Proceedings. Atenas, 2002. p.593.

11. Vandenberghe $K$, Van Hecke P, Van Leemputte M, Vanstapel F, Hespel P. Phosphocreatine resynthesis is not affected by creatine loading. Med Sci Sports Exercise 1999;31:236-42.

12. Bar-Or $\mathrm{O}$. The Wingate anaerobic test: an update on methodology, reliability and validity. Sports Med 1987;4:381-94

13. Havenetidis $\mathrm{K}$, Matsouka $\mathrm{O}$, Cooke CB, Theodorou A. The use of varying creatine regimes on sprint cycling. J Sports Sci Med 2003;2:88-97.

14. Snow RJ, Murphy RM. Factors influencing creatine loading into human skeletal muscle. Exercise Sport Sci Rev 2003;31:154-8.

15. American College of Sports Medicine. Position stand: progression models in resistance training for healthy adults. Med Sci Sports Exerc 2002;34:364-80.

16. Gordon CC, Chumlea WC, Roche AF. Stature, recumbent length, and weight. In: Lohman TG, Roche AF, Martorell R., editors. Anthropometric standardization reference manual. Champaign: Human Kinetics; 1988. p.3-8.

17. Hespel P, Op't Eijnde B, Van Leemputte M. Opposite actions of caffeine and creatine on muscle relaxation time in humans. J Appl Physiol 2002;92:513-8.

18. Green AL, Simpson EJ, Littlewood JJ, Macdonald IA, Greenhaff PL. Carbohydrate ingestion augments creatine retention during creatine feeding in humans. Acta Physiol Scand 1996;158:195-202.

19. Havenetidis K, Matsouka O, Konstadinou V. Establishment of the highest peak anaerobic power prior to the commencement of the anaerobic Wingate test. J Hum Mov Stud 2003;44:479-87.

20. Okano AH, Dodero SR, Coelho CF, Gassi E, Altimari, LR, Silva CC et al. Efeito da aplicação de diferentes cargas sobre o desempenho motor no teste de Wingate. Rev Bras Ciên e Mov 200;9:39-44.

21. Rawson ES, Perski AM, Price TB, Clarkson PM. Effects of repeated creatine supplementation on muscle, plasma, and urine creatine levels. J Strength Cond Res 2004;18:162-7.

22. Narayanan S, Appleton HD. Creatinine: a review. Clin Chem 1980:26:1119-26.

23. Barr SI, Rideout CA. Nutritional considerations for vegetarian athletes. Nutrition 2004;20:696-703.
24. Odland LM, Macdougall JD, Tarnopolsky MA, Elorriaga A, Borgmann A. Effect of oral creatine supplementation on muscle [PCr] and short-term maximum power output. Med Sci Sports Exercise 1997;29:216-9.

25. Cooke WH, Grandjean PW, Barnes WS. Effect of oral creatine supplementation on power output and fatigue during bicycle ergometry. J Appl Physiol 1995;78:670-3.

26. Dawson B, Cutler M, Moody A, Lawrence S, Goodman C, Randall N. Effects of oral creatine loading on single and repeated maximal short sprints. Aust J Sci Med Sport 1995;27:56-61.

27. Snow RJ, Mckenna MJ, Selig SE, Kemp J, Stathis CG, Zhao S. Effect of creatine supplementation on sprint exercise performance and muscle metabolism. J Appl Physiol 1998;84:1667-73.

28. Ledford A, Branch JD. Creatine supplementation does not increase peak power production and work capacity during repetitive wingate testing in women. J Strength Cond Res 1999;13:394-9.

29. Earnest CP, Snell PG, Rodriguez R, Almada AL, Mitchell TL. The effect of creatine monohydrate ingestion on anaerobic power indices, muscular strength and body composition. Acta Physiol Scand 1995;153:207-9.

30. Casey A, Constantin-Teodosiu D, Howell S, Hultman E, Greenhaff PL. Creatine ingestion favorably affects performance and muscle metabolism during maximal exercise in humans. Am J Physiol 1996;271:31-7.

31. Green JM, Mclester Jr JR, Smith JE, Mansfield ER. The effects of creatine supplementation on repeated upper- and lower-body Wingate performance. J Strength Cond Res 2001;15:36-41.

32. Tarnopolsky MA, Maclennan DP. Creatine monohydrate supplementation enhances high-intensity exercise performance in males and females. Int J Sport Nutr Exercise Metab 2000;10:452-63.

33. Kurosawa Y, Hamaoka T, Katsumura T, Kuwamori M, Kimura N, Sako T et al. Creatine supplementation enhances anaerobic ATP synthesis during a single $10 \mathrm{sec}$ maximal handgrip exercise. Mol Cell Biochem 2003;244:105-12.

34. Birch R, Noble D, Greenhaff PL. The influence of dietary creatine supplementation on performance during repeated bouts of maximal isokinetic cycling in man. Eur J Appl Physiol Occup Physiol 1994;69:268-70.

35. Havenetidis K, Cooke CB, King RFGJ, Butterly R. The effect of creatine supplementation on repeated $30 \mathrm{~s}$ cycle sprints in man. J Physiol 1995;483:S122.

36. Greenhaff PL, Casey A, Short AH, Harris R, Söderlund K, Hultman E. Influence of oral creatine supplementation on muscle orque during repeated bouts of maximal voluntary exercise in man. Clin Sci 1993;84:565-71.

37. Harris RC, Söderlund K, Hultman E. Elevation of creatine in resting and exercised muscle of normal subjects by creatine supplementation. Clin Sci 1992;83:367-74.

38. Greenhaff PL, Bodin K, Söderlund K, Hultman E. Effect of oral creatine supplementation on skeletal muscle phosphocreatine resynthesis. Am J Physiol 1994;266:725-30.

39. Vandewalle H, Peres G, Monod H. Standard anaerobic exercise tests. Sports Med 1987;4:268-89.

40. Weinstein Y, Bediz C, Dotan R, Falk B. Reliability of peak-lactate, heart rate, and plasma volume following the Wingate test. Med Sci Sports Exercise 1998;30:1456-60.

41. Prevost MC, Nelson AG, Morris GS. Creatine supplementation enhances intermittent work performance. Res Q Exercise Sport 1997;68:233-40.

42. Andrews R, Greenhaff PL, Curtis S, Perry A, Cowley AJ. The effect of dietary creatine supplementation on skeletal muscle metabolism in congestive heart failure. Eur Heart J 1998;19:617-22.

43. Rieu M, Duvallet A, Scharapan L, Thieulart L, Ferry A. Blood lactate accumulation in intermittent supramaximal exercise. Eur J Appl Physiol Occup Physiol 1988;57:235-42.

44. Havenetidis K, Bourdas D. Creatine supplementation: effects on urinary excretion and anaerobic performance. J Sports Med Phys Fitness 2003:43:347-55. 